\title{
Clinical and Histological Characteristics of Nasopharyngeal Cancer in Sokoto, North Western, Nigeria
}

\author{
Les Caractéristiques cliniques et Histological de Cancer Nasopharyngeal dans Sokoto, le Nord de \\ L'Ouest, le Nigeria
}

\author{
K. R. Iseh*, A. Abdullahi ${ }^{\dagger}$, S. A. Malami ${ }^{*}$
}

\begin{abstract}
BACKGROUND: Cancer of the nasopharynx poses diagnostic and therapeutic difficulties because of the hidden nature of the nasopharyngeal space, which allows for significant spread of the disease before diagnosis and hence poor prognosis.

OBJECTIVE: To describe the clinical and histological characteristics of nasopharyngeal cancer in a tertiarty health institution in Northern Nigeria.

METHODS:Clinical features of patients with nasopharyngeal cancer presenting at the Ear, Nose and Throat clinic of a University Teaching Hospital in North western Nigeria seen over a five-year period were analysed.

RESULT: A total number of 30 cases, [22(73.3\%) males and $8(27.7 \%)$ females] with a male to female ratio of $2.8: 1$ were seen. The mean age was 39.1years with the fourth decade of life recording the highest number of 16 cases $(53.3 \%)$ and the least in the thirth decade. The commonest clinical features were neck swelling caused by cervical lymphadenopathy $28(93.3 \%)$, epistaxis $25(83.3 \%)$, nasal obstruction $20(66.7 \%)$, and deafness $11(36.7 \%)$. Others were otalgia $9(30 \%)$, palatal swelling $\mathbf{8}(26.7 \%)$,cranial nerve involvement $7(23.3 \%)$ and visual impairment $6(20 \%)$. According to the UICC 1997 staging for nasopharyngeal carcinoma,23(76.7\%) and $7(23.3 \%)$ were $\mathrm{T} 3$ and T4 or stages III and IV respectively.The histological diagnoses were squamous cell carcinoma $23(76.7 \%$ ) cases, non-Hodgkins lymphoma 3(10\%) cases, plasmacytoma $2(6.7 \%)$ cases, rhabdomyosarcoma one $(3.3 \%)$ case, karposis sarcoma one $(3.3 \%)$ cases. Seventeen $(56.7 \%)$ patients though accepted in principle never went for radiotherapy. Only $2(6.7 \%)$ were still alive three and six years respectively from the time of diagnosis after chemoradiation while all others $(\mathbf{9 3 . 3 \%})$ had died within one year of diagnosis.

CONCLUSION: Nasopharyngeal cancer in Northern Nigeria is characterised by presentation with advanced disease, high mortality and low 5-year survival rates. Free or highly subsidized medical programme for early detection and treatment will reduce the high mortality rate associated with nasopharyngeal cancer in this region. WAJM 2009; 28(3): 151-155.
\end{abstract}

Keywords: Nasopharyngeal cancer, squamous cell carcinoma, high mortality, North-western Nigeria.

\section{RESUME}

CONTEXTE: le Cancer du nasopharynx pose des difficultés diagnostiques et thérapeutiques à cause de la nature cachée de l'espace nasopharyngeal, qui tient compte de la propagation significative de la maladie avant le diagnostic et le dorénavant pauvre pronostic.

Objectif : décrire les caractéristiques cliniques et histological de cancer nasopharyngeal dans une institution de santé tertiarty dans le Nigeria du Nord.

METHODES:Clinical de patients avec la présentation de cancer nasopharyngeal à l'Oreille, le Nez et la clinique de Gorge d'un Hôpital d'Enseignement d'université dans le Nigeria de l'Ouest Nord vu sur une période (un point) de cinq années ont été analysés.

RÉSULTATS : un nombre total de 30 cas, [22 (73.3\%) les mâles et 8 (27.7\%) les femelles] avec un mâle au rapport femelle de 2.8:1 a été vu. L'âge moyen était 39.1 ans avec la quatrième décade de vie enregistrant le plus haut nombre de 16 cas $(53.3 \%)$ et le moindre dans la décade thirth. Les traits cliniques les plus communs étaient l'enflure de cou provoquée(causée) par le collet lymphadenopathy 28 (93.3\%), epistaxis 25 (83.3\%), l'obstruction nasale 20 (66.7\%) et la surdité 11 (36.7\%). D'autres étaient otalgia 9 (30\%), l'enflure palatale $8(26.7 \%)$, la participation de nerf crânienne $7(23.3 \%)$ et l'affaiblissement visuel 6 (20\%). Selon 1997 UICC en organisant pour le carcinome nasopharyngeal, 23 (76.7\%) et 7 (23.3\%) étaient T3 et T4 ou les stades III et IV respectivement. Les diagnostics de histological étaient le carcinome de cellule squamous 23 cas (de 76.7 $\%)$, non-Hodgkins lymphoma 3 cas (de $10 \%$ ), plasmacytoma 2 cas (de $6.7 \%$ ), rhabdomyosarcoma un cas (de $3.3 \%$ ), karposis le sarcome cas (de $3.3 \%$ ). Dix-sept patients (de $56.7 \%$ ) bien qu'accepté ne sont allés en principe jamais pour la radiothérapie. Seulement 2 (6.7\%) étaient toujours vivants trois et six ans respectivement à partir du temps de diagnostic après chemoradiation pendant que tous les autres (93.3\%) étaient morts pendant un an de diagnostic.

CONCLUSION : le cancer de Nasopharyngeal dans le Nigeria du Nord est caractérisé par la présentation avec la maladie avancée, la haute mortalité et les taux de survie bas de 5 années. Le programme médical libre ou hautement subventionné pour la première détection et le traitement réduira le haut taux de mortalité associé au cancer nasopharyngeal dans cette région. WAJM 2009; 28 (3) : 151-155.

Mots clé : le cancer de Nasopharyngeal, squamous le carcinome de cellule, la haute mortalité, du nord-ouest, le Nigeria.

Departments of Ear, Nose \& Throat, Pathology, Usmanu Danfodiyo University Teaching Hospital, Sokoto, Nigeria

*Correspondence: Dr K R Iseh, Department of Ear Nose and Throat, Usmanu Danfodiyo University Teaching Hospital, Sokoto, Nigeria

E-mail: frobih@yahoo.com

Abbreviations: DNA, Deoxyrebonucleic acid; EBV, Ebstein Barr virus; NPC, Nasopharyngeal cancer; UICC, Union International Centre le Cancer; WHO, World Health Organisation. 


\section{INTRODUCTION}

The nasopharyngeal space being hidden allows for significant spread of nasopharyngeal cancer before any useful medical intervention is carried out. Ignorance of the peculiar clinical features of nasopharyngeal cancer allows for the spread of this disease to advanced stage before presentation to the Otolaryngologist. Nasopharyngeal cancer (NPC) accounts for $18 \%$ of all malignant neoplasms in the Cantonese. ${ }^{1}$ The highest incidence has been reported from Guang dong province of southern china where it is the third most common malignancy among men with an incidence rate of between $15-50$ per population. ${ }^{2-3}$ High incidences are seen among Hong Kong and Singapore Chinese. ${ }^{2-3}$ In Singapore it is the second most common tumour with $87 \%$ being chinese. ${ }^{1}$ Emigration from high to low incidence areas such as the USA and Canada reduces the incidence of nasopharyngeal cancer in the first generation Chinese but still remains at seven to eight times the rate in the whites. ${ }^{1-3}$ American-born secondgeneration Chinese have a lower risk of nasopharyngeal cancer than those born in China suggesting that both environmental and genetic factors are important. ${ }^{1}$ In Europe, nasopharyngeal cancer forms less than $6 \%$ of all head and neck cancers while in north America it constitutes 3\% of head and neck cancers. ${ }^{1-2}$ Elmes and Baldwin in 1947, reported one case of nasopharyngeal cancer amongst 1,000 tumours reviewed in Nigeria. ${ }^{4-5}$ Martinson is credited with first extensive work on nasopharyngeal cancer in south western Nigeria in 1968 when he described 56 cases and in 1984 when he reported on 180 cases. ${ }^{5-6}$ Okeowo in Lagos, also in south western Nigeria reported on nasopharyngeal cancer but surprisingly observed in his series a predominantly Ibo speaking tribe in a predominantly Yoruba speaking environment. ${ }^{7-8}$ Reports from the eastern, north central, north and south eastern Nigeria have highlighted various diagnostic, therapeutic difficulties, patterns and distant metastasis associated with nasopharyngeal cancer. ${ }^{9-}$ ${ }^{13}$ No study has shown the pattern from the north western region of Nigeria.This paper tries to present the pattern seen at a tertiary health institution from the region which serves as a referral centre to specialist, general and private hospitals in the region.

\section{SUBJECTS, MATERIALS A ND METHODS}

Clinical and histological characteristics of all patients who were diagnosed as nasopharyngeal cancer presenting at the Ear Nose and Throat Department of Usmanu Danfodiyo University Teaching Hospital were analysed from August 1999 to July 2005. The criteria for clinical diagnosis were: presence of or a combination of cervical lymphadenopathy, nasal obstruction, nasopharyngeal mass, epistaxis, otological symptoms such as hearing loss or ear discharge and cranial nerve or orbital involvement. This was then confirmed by histological diagnosis of specimens obtained from the nasopharynx either under general anaesthesia or under local anaesthesia through a pernasal biopsy.

Plain radiological investigation of the paranasal sinuses, especially skull base view (submentovertical view), soft tissue $\mathrm{X}$-rays of the neck, and chest $\mathrm{X}$-ray were done on all patients. Because majority of patients in this locality could not afford the costs of extensive investigations, clinical features, plain radiographs of the skull base with, histological diagnosis of biopsied tissue specimen from the nasopharynx, were sufficient to establish a diagnosis so as not to delay further management measures as most of them presented in advanced stages (Figure1) . Computerized tomographic scan was carried out only in 4 patients to exclude intracranial extension.

Examination under anaesthesia and biopsy of the nasopharynx was carried out in all patients except in two who had pernasal biopsy because they were considered too ill to withstand general anaesthesia. Patients who had extensive tumours of the nose and paranasal sinuses with nasopharyngeal extension or extensive angiofibromatous lesions of the nasopharynx confirmed by histological diagnosis were excluded from the study.

When the histological diagnosis confirmed nasopharyngeal cancer, patients were referred for radiotherapy at centres 5-12hours drive away (Zaria, Abuja or Ibadan) depending on the patient's preference of the one nearest to his locality. When there was unwillingness to travel to such centres immediately or the likelihood that patients may sign against medical advice and resign to fate, chemotherapy with the cheapest combinations of chemotherapeutic agent consisting of cyclophosphamide, methoxtrexate, vincristine, 5 flouracil as palliative measures was offered with the hope that regression of lesions will be convincing enough for patient and relatives to make every effort to travel for radiotherapy.

Tracheostomy was done in two patients who presented with massive neck swelling with upper airway obstruction.

\section{RESULTS}

A total number of 30 cases were seen. There were 22(73.3\%) males and 8(27.7\%) females with a male to female ratio of 2.8:1. The age range was from $14-60$ years. The mean age was 39.1 years with the $4^{\text {th }}$ decade of life (31-40years) recording the highest number of 16 cases (53.3\%). The lowest frequency of $3.3 \%$ was recorded in the $3^{\text {rd }}$ decade of life. Nasopharyngeal cancer spanned the $2^{\text {nd }}$ to the $6^{\text {th }}$ decade of life in this series with no case recorded in the first decade.

The commonest clinical features were neck swelling caused by cervical lymphadenopathy in $28(93.3 \%)$ cases, epistaxis in $25(83.3 \%)$ cases, nasal obstruction in 20 cases (66.7\%), and deafness in $11(36.7 \%)$ cases. Others were otalgia in nine $(30 \%)$ cases, palatal swelling in eight $(26.7 \%)$ cases, cranial nerve involvement in eight $(26.7 \%)$ cases visual impairment in six (20\%) cases and proptosis in four (13.3\%) cases.

Table 1: Distribution of Patients with Nasopharyngeal Cancer by Age and Sex

\begin{tabular}{ccll}
\hline \multirow{2}{*}{ Age (years) } & \multicolumn{2}{l}{ Number(\%) } \\
\cline { 2 - 4 } & Male & Female & \multicolumn{1}{l}{ Total } \\
\hline $0-10$ & 0 & 0 & 0 \\
$11-20$ & $2(6.6)$ & $2(6.6)$ & $4(13.3)$ \\
$21-30$ & $1(3.3)$ & 0 & $1(3.3)$ \\
$31-40$ & $12(40.0)$ & $4(13.3)$ & $16(53.3)$ \\
$41-50$ & $4(13.3)$ & $1(3.3)$ & $5(16.7)$ \\
$51-60$ & $3(10.0)$ & $1(3.3)$ & $4(13.3)$ \\
\hline & $22(73)$ & $8(27)$ & $30(100)$ \\
\hline
\end{tabular}


According to the UICC 1997 edition of staging for nasopharyn-geal carcinoma, $23(76.7 \%)$ and $7(23.3 \%)$ were $\mathrm{T} 3$ and $\mathrm{T} 4$ or stages III and IV respectively. ${ }^{1}$

The decreasing frequencies cases histological diagnosis were squamous cell carcinoma, non-Hodgkins lymphoma, plasmacytoma, rhabdomyosarcoma (1) $(3.3 \%)$ and Karposi's sarcoma. Only two $(6.7 \%)$ were still alive three and six years respectively from the time of diagnosis after chemoradiation while all others $(93.3 \%)$ have died within one year of diagnosis.

After several persuasions, 13 patients $(43.3 \%)$ accepted to travel for chemoradiation at an oncological centre with radiotherapy services. Most of these patients never completed their course of radiotherapy.Seventeen patients $(56.7 \%)$ though accepted in principle never went

Table 2: Clinical Features of Nasopharyngeal Cancer

\begin{tabular}{lc}
\hline Clinical Feature & Number(\%) \\
\hline Neck & \\
Enlarged cervical & \\
lymphnodes & $28(93.3)$ \\
Neck pain & $7(23.3)$ \\
Rhinological & \\
Epistaxis & $25(83.3)$ \\
Nasal obstruction & $20(66.7)$ \\
Otological & \\
Conductive deafness & $11(36.7)$ \\
Otalgia & $9(30.0)$ \\
Neuro-ophthalmic & \\
Cranial nerve palsy & $8(26.7)$ \\
Visual impairement & $6(20.0)$ \\
Proptosis & $4(13.3)$ \\
Oropharyngeal/Laryngeal \\
Palatal swelling & $8(26.7)$ \\
Voice changes & $7(23.3)$ \\
Dysphagia & $4(13.3)$ \\
Dypsnoea & $3(10.0)$ \\
\hline
\end{tabular}

Table 3: Histological Types of Nasopharyngeal

\begin{tabular}{lc}
\hline Histological type & Number(\%) \\
\hline Squamous cell carcinoma & $23(76.7)$ \\
Non-Hodgkin's lymphoma & $3(10.0)$ \\
Plasmacytoma & $2(6.7)$ \\
Rhabdomyosarcoma & $1(3.3)$ \\
Kaposi's sarcoma & $1(3.3)$ \\
\hline Total & $\mathbf{3 0}(\mathbf{1 0 0})$ \\
\hline
\end{tabular}

for radiotherapy. These patients made up the bulk of patients who received chemotherapy as palliative measures in the department of otorhinolaryngology as there was no oncologist on ground.

\section{DISCUSSION}

Nasopharyngeal cancer has been reported as the commonest head and neck cancer by Nwawolo et al in Lagos(south west Nigeria) (16.8\%), ${ }^{14}$ Ahmad et al in Maiduguri (North-Eastern Nigeria) $(46,8 \%),{ }^{11}$ Lily-tarriah et al Jos (North Central Nigeria) $)^{12-13}$ and among adults in North-western Nigeria (11.5\%). ${ }^{15}$ In Saudi Arabia, nasopharyngeal cancer is the commonest head and neck cancer $(33 \%)$ ${ }^{16}$. Although the number from this series is small when compared to other reports, there are perculiarities and similarities in several ways. In this study nasopharyngeal cancer affected more males (22 cases) $(73.3 \%)$ than females (8 cases) $(23.3 \%)$ with a male to female ratio of 2.8:1 and a mean age of 39.1years. The $4^{\text {th }}$ decade of life(31-40years) was the most affected with 16 cases $(53.3 \%)$. Nwaorgu et al reported a male to female ratio of 2.3:1 with an overall mean age of 41.1 years, in Ibadan south western Nigeria. ${ }^{16}$ In that study the peak age group for the females was 20-29 years and 50-59 years for males with age range of $10-81$ years. ${ }^{17}$ In this study the youngest age was 14 years and none was recorded in the first decade of life. It is possible that children with nasopharyngeal cancer were missed in this report as paediatric malignancies are managed by the paediatricians in our centre who may have a different approach to such lesions in diagnosis and treatment. Among the Caucasians, the incidence begins to rise in the second decade of life and peaks in the fourth and fifth decade with a male to female ratio of approximately $3: 1 .^{1-3}$

\section{Clinical Features}

Cervical lymphadenopathy in 28 cases $(93.3 \%)$ presenting as neck swelling was the commonest mode of presentation in this study and this is similar to most other reports. Sometimes the neck swelling was very massive in our series compromising the airway necessitating tracheostomy in two patients (Figure 1). Gobally about $50-90 \%$ of patients present

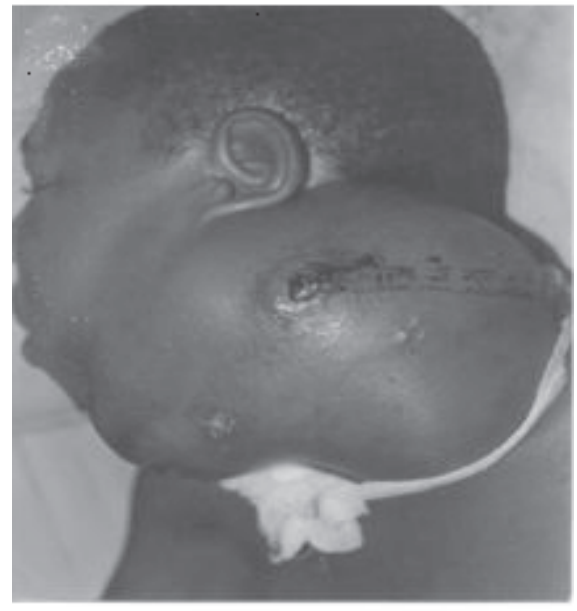

Figure 1: Massive Cervical Lymphadenopathy of a case of Nasopharyngeal Cancer that required Tracheostomy.

with cervical lymphadenopathy followed by nasal symptoms such as epistaxis and nasal obstruction, otologic symptoms, and neuro ophthalmic symptoms. ${ }^{2-3}$ If a patient presents with only cervical adenopathy, the finding of EBV genomic material in the tissue after amplification of DNA with the polymerase chain reaction lends strong evidence for a nasopharyngeal primary tumor, and a concerted search should be conducted in that area. ${ }^{2}$

In some countries or centres, the nasal symptoms are the most common presentation. ${ }^{1}$ Epistaxis in 25 cases $(83.3 \%)$ and nasal obstruction in 20 cases $(66.7 \%)$ were the nasal clinical features in this study. This usually results from growth of the tumour and erosion of blood vessels. Correction of anaemia from long standing blood loss is imperative before the commencement of chemotherapy and radiotherapy. Conductive deafness was recorded in 11 patients $(36.7 \%)$. A progressive unilateral hearing loss in an adult associated with nasal and neck symptoms must be screened to exclude nasopharyngeal cancer. Eustachian tube obstruction at its nasopharyngeal opening by the tumour and the loss of negative pressure with exudation of fluid into the middle ear cavity causing serous otitis media is responsible for the deafness.

Neuro-ophthalmic complications such as cranial nerve palsy in 8 cases (26.7\%), visual impairment in 6 cases (20\%) and proptosis in 4 cases $(13.3 \%)$ were recorded in this study. They signify 
advanced disease with poor prognosis. Late presentation was also another feature in this study. The patients in this study presented at either stages III $(76.7 \%)$ or IV $(23.3 \%)$ of UICC classification for nasopharyngeal cancer with bad prognosis. For locally advanced disease (stages III and IV), despite good initial response to radiotherapy, local recurrence and subsequent systemic failure are significant problems. ${ }^{3}$ When these patients further delay or do not want to go for radiotherapy or do not continue with the cycles of chemoradiation, their survival rates is further jeopardized and may be the reason why $28(93.3 \%$ )out of 30 cases have died within one year of diagnosis. Poverty and ignorance are the main reasons responsible for late presentation. The longest survivor (6 years) in this study was well educated who was ready to undergo the complete course of the oncological treatment with chemoradiation and to seek for financial assistance irrespective of the cost and distance to the radiotherapy centre.

\section{Prognostic Factors}

An estimated $50-65 \%$ of nasopharyngeal patients would present with locally advanced disease and about 5-8\% would have disseminated disease at the onset. ${ }^{18-19}$ Major prognostic factors adversely influencing outcome of treatment include: Large tumor size, a higher tumor (T) stage and the presence of involved neck nodes. ${ }^{18,20}$ Other factors linked to diminished survival that were present in some, but not all, studies include: age, nonlymphoepithelial histology, long interval between biopsy and initiation of radiation therapy, diminished immune function at diagnosis, incomplete excision of involved neck nodes, pregnancy during treatment, locoregional relapse, certain EBV antibody titre patterns..$^{18,20}$

The histological diagnosis in this study were squamous cell carcinoma 23 cases $(76.7 \%)$, non-Hodgkins lymphoma 3 cases (10\%), plasmacytoma 2 cases $(6.7 \%)$, rhabdomyosarcoma one case (3.3\%), and karposis sarcoma one case (3.3\%). Squamous cell carcinoma constitutes $85 \%$ of all malignant tumours of the nasopharynx while other types make up the rest. ${ }^{1}$ There was no consistent categorisation of the types of the squamous cell carcinoma in this study. The World Health Organisation (WHO) has divided nasopharngeal carcinoma into 3 types (all being varieties of squamous cell carcinoma) namely: 1) Keratinizing squamous carcinoma which could be well, moderately or poorly differentiated, 2) Non-keratinizing carcinoma, 3) Undifferentiated carcinoma. ${ }^{1}$ Poorly differentiated or undifferentiated carcinoma are more sensitive to radiotherapy. Poorly differentiated squamous cell cancer has been associated with EBV antibodies. ${ }^{1-3,20-21}$ High-titre antibodies to virus capsid antigen and early antigen, especially of high IgA class, or high titre that persist after therapy, have been associated with a poorer prognosis. ${ }^{1-3,18,21-22}$.

\section{Treatment}

Single and combination chemotherapy have been used as an adjunct to radiation in an attempt to achieve better local and systemic control. ${ }^{23}$ The head and neck intergroup study reported by Al-Sarraf et al which used a combination of concurrent chemoradiation followed by adjuvant chemotherapy achieved a significant difference in 5 years overall and progression free survival. ${ }^{24}$ Small cancers of the nasopharynx are highly curable by radiation therapy and patients with these small cancers have shown survival rates of $80 \%$ to $90 \% .{ }^{25}$ Moderately advanced lesions without clinical evidence of spread to cervical lymph nodes are often curable and patients with these lesions have shown survival rates of $50 \%$ to $70 \% .{ }^{18}$ Patients with advanced lesions, especially those associated with clinically positive cervical lymph nodes, cranial nerve involvement, and bone destruction have disease that is poorly controlled locally by radiation therapy with or without surgery, and the lesions often develop distant metastases despite local control. ${ }^{26-27} \mathrm{Al}$-Sarraf by reversing the sequence of chemotherapy delivery to neoadjuvant chemotherapy followed by chemoradiation reported a $90 \%$ overall 5 year survival. ${ }^{28}$

\section{Sokoto Experience}

Despite the innovations in nasopharyngeal cancer treatment, the awareness of nasopharyngeal cancer is still generally inadequate both among the general population and the health personnel in our environment. Most of these patients were initially and wrongly treated as catarrh. Nigerians pay for their health care and the indigent ones which sadly are the most affected by disease cannot afford the cost of oncological treatment located in few designated centres because of low income. Newer chemotherapeutic agents are equally expensive and motivation to continue the cycles is a herculean task physicians and surgeons face while persuading patients to continue. The long distances to radiotherapy centres is quite enormous for very ill patients; who still need to go and queue for their turn.

A mortality of $93.3 \%$ per year of patients in this study of a predominantly young population needs urgent measures to reverse the trend in the region politically, socially, and economically, not just academically as useful manpower to the nation is lost to ravages of nasopharyngeal cancer in the region. Health education, continuing medical education is what we must consistently address. Given adequate facilities, the 5-year survival rate which currently has reason to $90 \%$ may be attenable. Free cancer screening, subsidy in cancer treatment and provision of more oncological centres equipped to offer radiotherapy services which is only available in four government and two private owned centers at rates which majority of the patients cannot afford in Nigeria will greatly improve the survival rates.

In conclusion, NPC in the northwestern Nigeria was mainly characterized by advanced disease (stages III and IV), unwillingness to travel for radiotherapy treatment $(57.6 \%)$ with high mortality rate $(93.3 \%)$. The mean age was 39.1 years with the highest incidence in the $4^{\text {th }}$ decade (53.3\%). Squamous cell carcinoma $(76.7 \%)$ was the commonest histological type. Efforts should be aimed at early detection of nasopharyngeal cancer and provision of free or highly subsidized oncological services. More radiotherapy centres for the region are needed which should be affordable and easily accessible. Cytogenetic and immunological studies should be funded liberally on nasopharyngeal cancer and indeed other 
cancers in Nigeria.

\section{REFERENCES}

1. Watkinson JC, Gaze MN, Wilson JA.The nature of head and neck cancer.In Stell and Maran's Head and Neck Surgery. $4^{\text {th }}$ edition,Oxford Butterworth-Heinemann, 2000: pg 1-8.

2. Sivanandan R, Fee WE. Benign and malignant tumours of the naso-pharynx. In: Cummings CW, Flint PW, et al (eds). Cummings Otolaryn-gology Head and neck surgery $4^{\text {th }}$ edition, Elsevier Mosby, 2005: 1672-1684.

3. HO JHC. An epidemiologic and clinical study of nasopharyngeal carcinoma. Int J Radiat Oncol Biol Phys 1978; 4: 181192.

4. Elmes GG, Baldwin RG. Malignant diseases in Nigeria: An analysis of a thousand tumours. Ann Trop Med Parasit 1947; 41: 321-328.

5. Martinson FD.Cancer of the nasopharynx in Nigeria. J Laryngol 1968; 82: $1119-1126$.

6. Martinson FD. Aghadiuno PU. Nasopharyngeal cancer in Nigeria. International Agency for research on cancer 1984; 63: 501-511.

7. Okeowo PA,Ajayi DOS,Cancer in Nigeria. Tropical Medicine Series University of Ibadan Press 1978: 117122.

8. Ketiku KK, Igbinoba F, Okeowo PA. Nasopharyngeal Cancer in Nigeria: A Revisit. Nig Postgrad Med J 1998; 5: 712.

9. Obiako MN. The diagnostic and therapeutic difficulties of nasopharyngeal cancer. Post Grad Doct Afr 1984; 7: 86-90.

10. Mezue WC,Ezeanolue BC. Nasopharyngeal cancinoma in the differential diagnosis of intracranial subtemporal. Afr
J Med Sc 1994; 23: 177-180.

11. Ahmad BM, Pindiga UH. Malignant neoplasms of the ear, nose and throat in northeastern Nigeria. Highland Medical Research Journal 2004; 2: 45-48.

12. Lilly-Tariah OB, Nwana EJ, Okeowo PA. Cancer of ear, nose and throat. Nigerian Journal of Surgical Science 2000; 10: 5256.

13. Lilly-Tariah OB, Somefun AO. Malignant tumours of the nasopharynx at Jos University Teaching Hospital, Nigeria. Niger Postgrad Med J. 2003; 10: 99102.

14. Nwawolo CC, Ajekigbe AT, Oyeneyin JO, Nwankwo KC, Okeowo PA. Pattern of head and neck cancers among Nigerians in Lagos. WAJM 2001;111-115.

15. Iseh KR,Malami SA.Patterns of head and neck cancers in sokoto. Nig Jour Otolaryn 2006; 3: 77-83.

16. Clubb BS, Quick CA, Amer MH, et al Nasopharyngeal carcinoma in Saudi Arabia: A retrospective study of 166 cases treated with curative intent. Int J Radiat Oncol Biol Phys 1988; 15: 111927.

17. Nwaorgu OGB, Ogunbiyi JO. Nasopharyngeal cancer at the University College Hospital Ibadan Cancer Registry: an update. WAJM 2004; 23: 135-138.

18. The National Cancer Institute. U.S National Institute of Health http:// www.cancer.gov/cancertopics/pdq/treatment/nasopharyngeal/healthprofessional Accessed September 2007.

19. Tan E, Leong S, Tan T, Fong K, Wee J. Multimodality management of nasopharyngeal carcinoma In: Adelstein DJ (ed). Squamous cell Head and neck cancer:Recent clinical progress and prospects for the future Human Press Inc, New Jersy 2005: 211-225.

20. Sanguineti G, Geara FB, Garden AS, et al.: Carcinoma of the nasopharynx treated by radiotherapy alone: determi-nants of local and regional control. Int J Radiat Oncol Biol Phys 1997; 37: 985-96.

21. Neel HB 3rd, Pearson GR, Taylor WF: Antibodies to Epstein-Barr virus in patients with nasopharyngeal carcinoma and in comparison groups. Ann Otol Rhinol Laryngol 1984; 93: 477-82.

22. Lin JC, Chen KY, Wang WY, et al.: Detection of Epstein-Barr virus DNA the peripheral-blood cells of patients with nasopharyngeal carcinoma: relationship to distant metastasis and survival. J Clin Oncol 2001; 19: 2607-15.

23. Lin JC, Jan JS, Hsu CY, et al. Phase III study of concurrent chemoradiotherapy versus radiation alone for advanced nasopharyngeal carcinoma:positive effect on overall and progression free survival. J Clin Oncol 2003; 21: 631-633.

24. Al-Sarraf M, LeBlanc M, Giri PG et al. Chemotherapy versus radiotherapy in patients with advanced nasopharyngeal cancer: phase III randomised intergroup study 0099. J Clin Oncol 1998;16: 13101317.

25. Bailet JW, Mark RJ, Abemayor E, et al.: Nasopharyngeal carcinoma: treatment results with primary radiation therapy. Laryngoscope 1992; 102: 965-72.

26. Fandi A, Altun M, Azli N, et al.: Nasopharyngeal cancer: epidemiology, staging, and treatment. Semin Oncol 1994; 21: 382-97.

27. Teo PM, Chan AT, Lee WY, et al.: Enhancement of local control in locally advanced node-positive nasopharyngeal carcinoma by adjunctive chemotherapy. Int J Radiat Oncol Biol Phys 1999; 43: 261-71.

28. Al-Sarraf M. Treatment of locally advanced head and neck cance: Historical and critical review cancer control 2002; 9: 387-388. 